\title{
Reviewing clinical guideline development tools: features and characteristics
}

\author{
Soudabeh Khodambashi ${ }^{*}$ (D) and Øystein Nytrø
}

\begin{abstract}
Background: To improve consistency and streamline development and publication of clinical guidelines (GL), there is a need for appropriate software support. We have found few specific tools for the actual authoring and maintaining of GLs, and correspondingly few analyses or reviews of GL development tool functionality. In order to assist GL developers in selecting and evaluating tools, this study tries to address the perceived gap by pursuing four goals: 1) identifying available tools, 2) reviewing a representative group of tools and their supported functionalities, 3) uncovering themes of features that the studied tools support, and 4) compare the selected tools with respect to the themes.

Methods: We conducted a literature search using PubMed and Google Scholar in order to find GL development tools (GDT). We also explored tools and Content Management Systems (CMS) used in representative organisations and international communities that develop and maintain GLs. By reading a selected representative group of five GL tool manuals, exploring tools hands-on, we uncovered 8 themes of features. All found tools were compared according to these themes in order to identify the level of functionality they offer to support the GL development and publishing process. In order to limit the scope, tools for designing computer-interpretable/executable GL are excluded.
\end{abstract}

Results: After finding 1552 published papers, contacting 7 organizations and international communities, we identified a total of 19 unique tools, of which 5 tools were selected as representative in this paper. We uncovered a total of 8 themes of features according to the identified functionalities that each tool provides. Four features were common among tools: Collaborative authoring process support, user access control, GL repository management, electronic publishing. We found that the GRADE methodology was supported by three of the reviewed tools, while only two tools support annotating GL with MeSH terms. We also identified that monitoring progress, reference management, Managing versions (version control), and Change control (tracking) were often the missing features.

Conclusion: The results can promote sector discussion and eventual agreement on important tool functionality. It may aid tool and $G L$ developers towards more efficient, and effective, $G L$ authoring.

Keywords: Clinical guideline, Guideline development tool, Electronic guideline authoring, Guideline development process

\section{Background}

Clinical practice guidelines (GL) are developed to provide evidence-based advice on diagnosis and treatment to clinicians at the point of care [1]. During the last two decades, major advances have been made in developing, disseminating and implementing GLs to improve healthcare outcomes [2]. Various guidelines on how to develop guidelines have been published, and standards are suggested for the development of trustworthy guidelines (guideline for guidelines) [3, 4]. The

\footnotetext{
* Correspondence: soudabeh@idi.ntnu.no

Department of computer and Information Science, Norwegian University of Science and Technology, Trondheim, Norway
}

process of authoring GLs is complex, time consuming, and usually involves large, often geographically distributed, multidisciplinary teams. It is common to develop a guideline as an academic text, by means of a document editor, and most often the final version, with summary recommendations, is published in print and guideline web portals and services.

Organizations responsible for developing and maintaining GLs adopt Content Management Systems (CMS) in order to manage concurrent authoring, revision, review and publishing. Our previous case study on information systems support for maintaining national GLs in Norway showed that the currently used information 
systems or CMS are neither fulfilling the authors' needs in terms of functionality, nor facilitating communication between authors developing guidelines collaboratively [5]. Different groups of researchers have proposed specialized software tools to ease the guideline development process while accommodating guideline authors' needs. Collectively, we describe these tools as 'guideline development tools' (GDT) [6-9].

Developers of GDTs have their own assumptions and points of views, which results in software with different functionalities and features. In addition, the proposed GDTs have different foci in the guideline development process. To the best of our knowledge, there is no peerreviewed paper analysing or comparing GDTs in detail. Therefore, characterising features supported by the GDTs, comparing them and presenting their area of focus were the main motivations behind this research. Consequently, this study has four main goals: 1) identifying available GDTs, 2) reviewing a representative group of GDTs and their supported functionalities, 3) uncovering themes of features that the studied GDTs support, and 4) compare the selected tools with respect to the themes.

We note that the scope of this study is limited to the GDTs for authoring GLs; therefore tools for guideline adaption and implementation are omitted. Furthermore, tools for authoring formalized (computer-interpretable) guidelines are also omitted, since they represent a distinct later step in GL development, overlapping with general software design and development tools that are well described in the research literature.

The rest of the article is organized as follows: The 'Method' section presents the search strategy to find GDTs and related CMSs, tool selection criteria, review method, and methods for uncovering themes. The 'Results' section presents the found GDTs, selected representative GDTs and themes of features. 'Discussion' tries to learn from the results, while 'Conclusion' acknowledges that tools must be tested in practice.

\section{Methods}

\section{Searching for guideline development tools}

We searched for peer-reviewed papers outlining relevant GDT or CMS in literature, contacted representative guideline development organisations and communities, and attended an international conference and a national meeting.

The primary literature search was performed using PubMed and Google Scholar in March 2015 and the last search was conducted in May 2016. The selection and review process was conducted according to PRISMA guidelines [10] and is presented in Fig. 1. Details of retrieved papers based on a combination of search keywords are presented in Table 1.
We reviewed the title and abstract of the retrieved papers. In case the title and abstract of the reviewed papers were not clear, we screened the full text. The two authors performed study selection in duplicate and discussed the inclusion or exclusion of papers until consensus was achieved.

In order to learn more about actual GDT in use, we contacted a sample of organizations and national/international communities with known GDT-related activity.

- Guideline International Network (G-I-N) [11].

- NICE (National Institute For Health and Clinical

Excellence), United Kingdom

- Agency for Healthcare Research and Quality (AHRQ), USA

- National Health and Medical Research Council

(NHMRC), Australia

- Norwegian Health Library (Helsebiblioteket)

- St. Olav's University Hospital Trust (Norway)

- Innlandet Hospital Trust (Norway)

In addition, participation in two conferences was another source of identifying GDTs:

- DECIDE International Conference (http://www.cebhc .co.za/decide-conference), in Edinburgh, 2014, conference theme: evidence-based guideline development.

- The Norwegian Directorate of Health supplier conference, in Oslo, 2014, conference theme: procurement of potential GDT for authoring national clinical guidelines.

The selection criteria of GDTs and CMSs for analysis We considered three main criteria:

1) Some tools offer only partial support of the GL authoring process. In order to select a representative set of tools for comparison, we systematically ranked more general tools, covering more steps in the authoring process, higher than tools covering fewer steps. In the end, we omitted GDTs that were fully subsumed by more comprehensive tools.

2) General-purpose CMS were not considered for review, only CMSs specifically supporting GL authoring.

3) We excluded tools that only covered GL adaption, localization and/or implementation. GL or evidence profile repositories were excluded.

\section{Method for analysing the GDTs and CMS}

We explored the GDTs and CMSs that we found in literature and organisations hands-on. We also analysed the provided manuals for each tool in order to identify the functionalities and features they support. If we questioned certain functionalities, we contacted the developing team directly. 


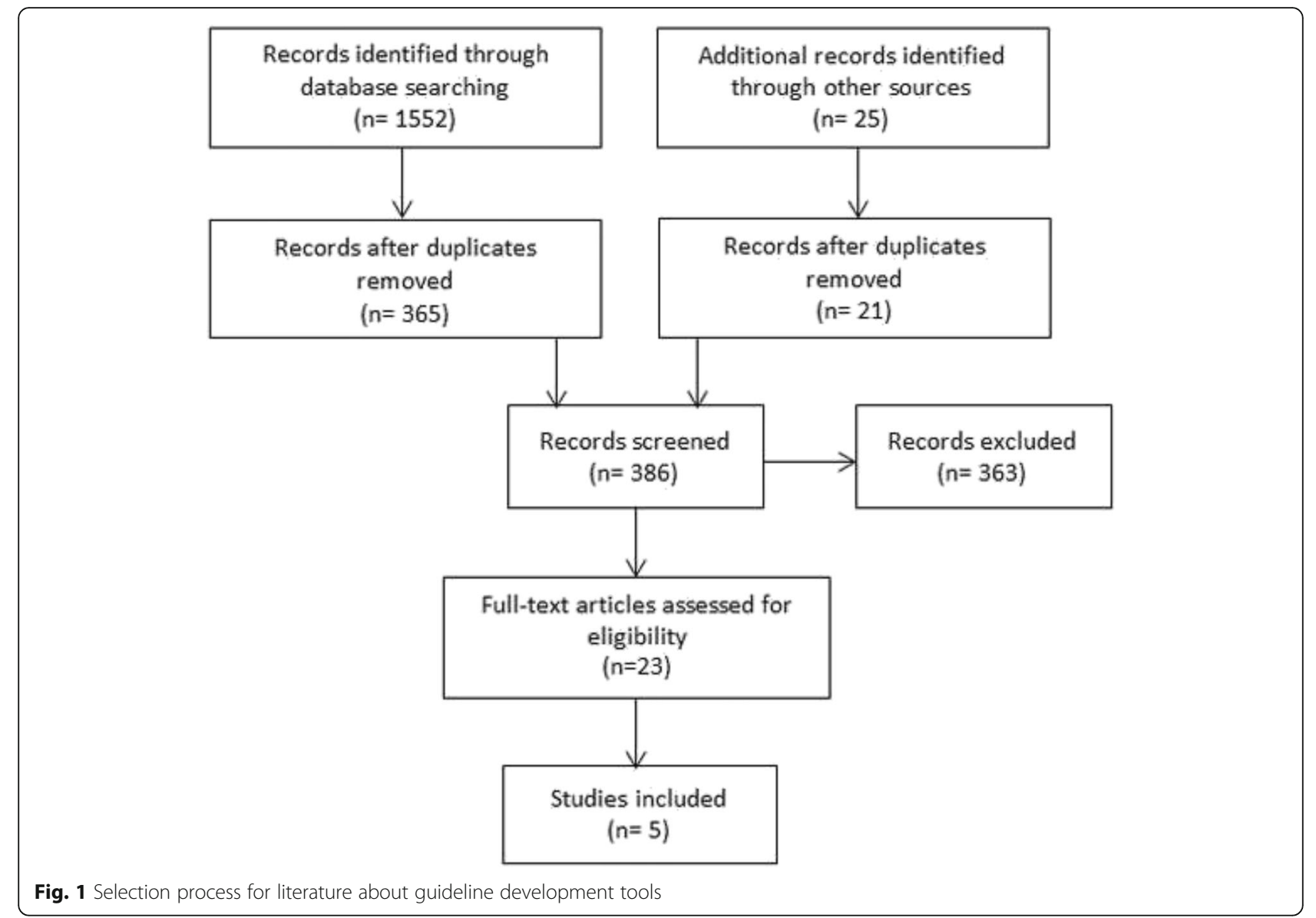

\section{Method for uncovering themes}

We uncovered themes of supported features and functionalities using the thematic synthesis method [12]. It allowed us to identify specific segments of text and recurring topics, label them, elicit high-level requirements and classify them into themes. Prose text descriptions were validated in seven brainstorming sessions between authors.

\section{Results}

The results according to the goals are: 1 ) identified GDTs and CMSs, 2) a selection of representative GDT, 3) a set of feature themes, and 4) a characterization of the selected tools according to the identified themes.

\section{The identified GDTs and CMSs}

The identified tools based on the searched sources are presented in the following sections.

\section{Details of the literature search}

Our literature search phrases and corresponding results were presented in Table 1 . We generally found that publications describe the individual tools and their use, rather than their functionalities. In Table 1, MAGICapp is the subject of [13-15], GRADEPro is the subject of [16-18], and Internet Portal for guideline development (henceforth "Internet Portal") is presented in [19, 20]. All the tools and methodologies reviewed by M. Peleg [21], except BRIDGE-Wiz [7], were aimed at computational representation, and require users to have programming knowledge or collaborate with knowledge engineers to encode guidelines; therefore, they are excluded from our study.

\section{Details of search in organizations}

The G-I-N have published a list of suggested tools on their website [22]. Again, we found MAGICapp, GRADEPro, and Internet Portal. The other suggested tools on the Website [22] are designed to support only part of the guideline development process. We categorise them below:

1) Adapt and implement existing guidelines: CANIMPLEMENT@ [23]

2) Make and publish summary of finding tables (SoF): DECIDE [24] 
Table 1 Search keywords and results of the literature review

\begin{tabular}{|c|c|c|c|c|}
\hline \multirow[t]{2}{*}{ Search phrases and keywords } & \multicolumn{2}{|l|}{ Google Scholar } & \multicolumn{2}{|l|}{ PubMed } \\
\hline & No. retrieved papers & No. relevant papers & No. retrieved papers & No. relevant papers \\
\hline $\begin{array}{l}\text { "content management system" } \\
\text { "clinical guideline" }\end{array}$ & 21 & 0 & 95 & $1[19]$ \\
\hline $\begin{array}{l}\text { "content management systems" } \\
\text { "clinical guideline" }\end{array}$ & 7 & 0 & 97 & 0 \\
\hline $\begin{array}{l}\text { "content management systems" } \\
\text { "clinical guidelines" }\end{array}$ & 39 & $2[19]$ & 139 & 0 \\
\hline $\begin{array}{l}\text { "content management system" } \\
\text { "clinical guidelines" }\end{array}$ & 91 & $2[19]$ & 149 & $1[19]$ \\
\hline $\begin{array}{l}\text { "content management system" } \\
\text { "guideline" "clinical" }\end{array}$ & 282 & $2[19]$ & 95 & $1[19]$ \\
\hline $\begin{array}{l}\text { "content management system" } \\
\text { "guideline" "clinical" "CMS" }\end{array}$ & 123 & $2[19]$ & 1 & 0 \\
\hline $\begin{array}{l}\text { "guideline development tool" } \\
\text { "guideline development" }\end{array}$ & 56 & $4[6,14,16,17]$ & 108 & 0 \\
\hline $\begin{array}{l}\text { "guideline authoring tool" } \\
\text { "guideline development" }\end{array}$ & 17 & $1[13]$ & 6 & 0 \\
\hline $\begin{array}{l}\text { "guideline authoring tools" } \\
\text { "guideline development" }\end{array}$ & 13 & $2[13,14]$ & 12 & $2[13,19]$ \\
\hline $\begin{array}{l}\text { "guideline development" } \\
\text { "software" "authoring tool" }\end{array}$ & 56 & $3[13,15,21]$ & 2 & 0 \\
\hline $\begin{array}{l}\text { "Development tool" and "clinical } \\
\text { guideline" }\end{array}$ & 69 & $1[18]$ & 28 & 0 \\
\hline $\begin{array}{l}\text { "Integrated Development Environment" } \\
\text { and "clinical recommendation" }\end{array}$ & 1 & 0 & 0 & 0 \\
\hline $\begin{array}{l}\text { "Integrated Development Environment" } \\
\text { and "clinical guideline" }\end{array}$ & 20 & 0 & 25 & 0 \\
\hline
\end{tabular}

3) Perform systematic review: Doctor Evidence platforms [25], RevMan 5 [26], Distiller [27], Rayyan [28], JBI-SUMARI [29], SRDR [30], EPPI-Reviewer 4 [31], CREBP SRA Systematic Review Creator [32] and Covidence [33]

4) Maintain systematic review repository: Epistemonikos [34], and SRDR [30]

5) Do semi-automated citation screening for systematic reviews: Abstrackr [35]

6) Maintain guideline repository: GIN guideline library [36]

7) Detect duplicates in systematic reviews: CREBP Systematic Review Assistant [37]

8) Maintain evidence profile repository: GDTs database of evidence profiles [38]

By contacting to the other organizations, we found that NICE and NHMRC have their own in-house CMS; AHRQ does not use any tools or CMS. We found that the Norwegian Health Library, the St. Olav's University Hospital Trust and the Innlandet Hospital Trust all used general-purpose CMS. The Norwegian Health Library piloted MAGICapp, and Innlandet Hospital Trust piloted purpose-built "Håndboka".

\section{Details of search in national/international communities}

The Decide conference and the supplier conference uncovered, again, MAGICapp [15] and GRADEpro [39]. The national supplier conference furthermore uncovered Håndboka.

\section{Selected tools for review}

According to the tool selection criteria presented in Section 2.2, the selected tools were: MAGICapp, GRADEpro, Internet Portal, BRIDGE-Wiz, and Håndboka. BRIDGE-Wiz [7] is designed to be used in the panel meeting to systematically create more transparent recommendations. BRIDGE-Wiz enhances implementation by letting authors state the strength of the recommendation, the level of obligation, and the balance between the benefits and harms [7]. Since the implemented features in BRIDGE-Wiz are different from other GDTs that fully support the GL development process, we included it in our analysis. The next section describes themes of features uncovered in these five GDTs.

\section{The uncovered themes of features}

Based on hands-on experience and the thematic analysis method, we identified a total of 8 themes representing 
GDTs features: 1) Team and contribution management, 2) Project management, 3) Evidence management, 4) Guideline development, 5) Document management, 6) Guideline content enhancement, 7) Import, export and publication, 8) User experience enhancement. A list of identified themes, their description and intension are presented in Table 2.

\section{Representative tools characterization}

We reviewed the five representative tools (MAGICapp, GRADEpro, BRIDGE-Wiz, Håndboka, and Internet Portal) based on the uncovered themes and present the results in in Table 3. In case the functionality/feature is not supported by the tool, we used '-' sign. Details of the results are presented in the see Additional file 1.

As shown in Table 3, four out of the five tools had common functionalities or features: collaboration, access control, guideline repository management, electronic publishing. The GRADE methodology is supported in three of the reviewed tools for rating of guideline recommendations. We found only two tools supporting $\mathrm{MeSH}$ annotation. We also identified that monitoring progress, reference management, managing versions (version control) and Change control (tracking) had least coverage. Results show that the identified themes and their features not only cover required functionalities and features for a GDT to support the guideline development process, but also include functionalities and features to improve guideline dissemination, guideline search, and integration of guideline recommendations to EHR. We note that we contacted the creators of the tools to confirm the results and our judgment.

\section{Discussion}

In this section we provide an analysis of the results with suggestions for improvement.

1) Conflict of Interest and user access

Although GRADEpro and Internet portal can manage conflict of interest (COI) and have role based user access, they lack fine-grained edit access for COIs on specific guideline sections. We recommend fine-grained access control and administrator roles on section/recommendation level with different restriction level.

2) Workflow support

The 'development checklist' and 'setting milestones and deadline' in MAGICapp are not integrated with workflow management. Similarly, GRADEpro does not track task completion based on the milestone manager. We recommend that GDTs interface with workflow management systems that can support the entire GL development process for distributed teams. In order to control and track how a guideline under development moves from one team member to another based on their contribution and track the steps, proper workflow management system support is necessary. A workflow model to manage content from initial draft to the publishable form would be an improvement. Plans milestones, checklists, progress of voting, review/approval should be considered. Progress monitoring at individual, group and project level is critically important. In addition, a workflow model should provide details about development/update, content changes, versions, feedback, task assignment, and active reminders. A customizable workflow management system can be used to tailor development to local practice.

3) Collaborative literature search and evidence analysis Evidence assessment is a collaborative process and authors may need to highlight or annotate the reviewed article. Our results show that only Internet Portal can import articles to a repository accessible to team members for further analysis, data extraction with the aim of making a systematic review. We recommend that GDTs supports annotation, annotation comments and storage of search results for each individual article.

4) Automatic tracking of changes and version control Developing guidelines is a collaborative process and change tracking is intertwined with development process and conflict resolution. We recommend that edit history, changes, forking, roll-backs and supporting user/role/group on the same granularity as COImanagement and voting. Furthermore, we recommend that versioning may be automatic and milestone-or interval-based so as to simplify use of long-term, continuous development processes.

5) Customizable guideline template We recommend that the GDT support use and creation of guideline templates. This may significantly lower effort for developing new or local versions of a GL, and it will help less experienced developer teams. A customizable template can be used to tailor development to local practice and potentially increase tool adoption

6) Usability of guideline development tools Usability is a core concern for any software tool. BRIDGE-Wiz has been evaluated [7], but we did find few specific results for GDT usability. That is not surprising, since software engineering considers usability part of practice, and not research. However, we recommend that user interface design, wizardbased and template-based authoring, interactive user guides, and workflow management support be thoroughly evaluated with respect to utility and usability.

7) Electronic GL publication and usability

In our previous studies about usability evaluation of GLs on the Web [40-43] we found that presentation 
Table 2 The identified themes and their features

\begin{tabular}{lll}
\hline Themes & Features & Description \\
\hline Team and contribution management & Collaboration & $\begin{array}{l}\text { Support guideline panel roles; Remote and synchronous/asynchronous } \\
\text { collaboration; Separate development, review, approval, etc. Allow both } \\
\text { central real-time collaboration and remote batch-wise check-in/out. }\end{array}$
\end{tabular}

Access

Role

Conflict of interest

Project management

Development checklist

Milestones and deadlines

Progress monitoring

Evidence management

Search strategy and history

Evidence repository

Citations and reference

Evidence assessment

Quality rating

Terminology and language

Voting
Enable logging; Authentication and authorization; Access policies and profiles; High granularity of access control; Separate between edit, comment, create, delete, review, vote, accept and other forms of access.

Support multiple roles per individual; Group roles (more than one person filling a role): Organizational roles; Dynamic roles according to process part and progress; Role inheritance and composition; Role-based access control; Dynamic roles according to voting and role delegation.

Handle and track panel members COI declarations [47]. Accept different organizational COls and content, for example: ICMJE [48], WHO [47], NHF (McMaster-NHF Guideline Panel conflict of interest form), and MSPSC [18].

Support development process phases, including evidence review, development, publication, evaluation, etc.; Support plans and plan templates; Progress monitoring and dashboards; Management of workload, work division and subprojects; Quality control and testing/validation;

Cfr. Suggested lists by Guideline International Network [49], AGREE [50], and GIN-McMaster Guideline Development Checklist [51].

Support for resource control and allocation, deliverable management

Review and revise and monitor steps/phases and degree of completion. Both for participants, audits and management.

Support search in literature, existing guidelines and systematic reviews and health technology assessment reports for latest evidence according to a strategy [52]. Record search strategy, sources, search keywords, retrieved results, filtering, inclusion and exclusion criteria and outcome.

Support storage of annotated literature and summaries in context; Provide sharing and collaborative assessment.

Record evidence background for a specific recommendation. Link to context (cite) and refer to bibliography in evidence repository.

Add, revise and delete background with justifications and assessment. Automate reference embedding and corresponding repository update.

Enable repeated assessment of articles and evidence; Document assessment including temporary and final decisions of relevance, currency and eligibility for inclusion. Support different methods for assessment rating, i.e. Scottish Intercollegiate Guidelines Network (SIGN) [53], Oxford [54], and GRADE [55].

Support different methodologies for rating the quality of evidence and ranking the strength of recommendations [56]. i.e. Grades of Recommendation Assessment, Development and Evaluation (GRADE) $[57,58]$, the American Academy of Paediatrics (AAP), American College of Emergency Physicians (ACEP), American Society of Clinical Oncology (ASCO), American Urological Association (AUA), American Society for Parenteral and Enteral Nutrition (ASPEN), and American Physical Therapy Association (APTA) $[7,56,59]$.

Support controlled natural language restricting the grammar and vocabulary in order to reduce or eliminate ambiguity and complexity [60]. Support limited sentence and recommendation forms to enhance consistency of expression. Deontic expressions ('must', 'should', 'may') can be used to add a semantics of intended level of obligation in the recommendation [7].

Support voting process, including voting rules, collecting casted votes, results presentations and recording. Record justifications and factors like evidence behind the recommendations, values, preferences and available resources in approving the recommendations. Document disagreement and consensus processes [52].

Since guideline development is a collaborative, complex editorial and review process, it is desirable to keep track of all the changes in the guideline content based on the collaborators user account in a 
Table 2 The identified themes and their features (Continued)

distinguishable and comprehensible way. All the modification on guideline (partially or fully) including metadata associated to the guideline should be trackable.

Managing versions (version control)

Since the guideline development process needs constant edition and update, successive iterations of a document have to be numbered and saved in the repository. The versioning control for a document library can include major versions and minor (draft) versions for the same guideline under development.

Template-based authoring

To ensure consistency, template-based authoring can assist authors by indicating the main subject headings that are necessary to be included in a guideline. For example, a guideline has to have title, background information, recommendation and references. Different organisations have different perspective on the main components that should be included in a guideline. Therefore, template-based authoring with certain flexibility in addressing different organizational perspectives for different types of guidelines is required.

Guideline repository management The guideline development process is a nonlinear process. A guideline has to be changed frequently before final approval for publication. Therefore, storing the guidelines under development, which is a living document, in a repository facilitates the development process significantly. It can include storing images and all related attachments to the guideline as well.

Guideline content enhancement Tagging and EHR linking

Support semi-automated tagging of recommendations with relevant classification as ICD [61], SNOMED-CT [62], ATC [63], RxNorm [64], MeSH [65], ICPC-2 [66], LOINC [67], and UMLS [68]. Support tagging content that may be retrieved from the EHR.

Import, export and publication Import and export file formats

Guidelines, templates, meta-data, roles, repositories, process data (fully or partially) to different templates and formats. Between projects, guidelines and tools.

Publishing

Wizard-based authoring

Export navigable and end-usable guidelines

User experience enhancement

Walkthrough user guide

User manual
Sequencing of steps in the guideline development process (fully or partially) in order to lead the authors through a series of well-defined steps.

A walkthrough user guide to provide a step-by-step overview of implemented functionalities in a guideline development tool to the users with no experience

Software user guide containing details on how to navigate and use the implemented functionalities. format, layout, navigation and search functionality were important [44]. GDTs affect publication format and functionality and thus guideline usability. For example, as MAGICapp and GRADEpro allow publishing on various platforms, which may be both a challenge and boon in practice. As another example, in our previous study we found that guideline users are concerned with credibility of recommendations; hence providing additional information with the graded recommendation would increase their confidence in choosing recommendations [43]. We recommend that GDTs provide or enable easy publication of references, author justification as well as evidence in a comprehensive, yet unobtrusive way.

8) Guideline annotation

EHR integration is very important, but relies on computational formalization, and domain modelling, which begins where we stopped. However, simple
GL annotation may enhance search and retrieval related to specific patients. MAGICapp describes EHR content in the GL, enabling the GL recommendations to be instantiated with current patient data.

The analysed GDTs in this paper are developed by a joint collaboration of multidisciplinary and international teams (MAGICapp (Norway, Canada, Spain, Germany, Scotland, Lebanon, and USA), GRADEPro (Canada, Chile, Brazil, USA, American University of Beirut, Spain, Italy, Germany, Norway, USA, UK, World Health Organization (Switzerland), Finland, and Denmark), BRIDGE-Wiz (USA), internet Portal (Germany), and Håndboka (Norway)), hence the presented results and findings will be applicable to other guideline development organisations in other countries.

Much research and development have gone into formalizing GLs to make them computer interpretable. The accompanying software development tools, or integrated 


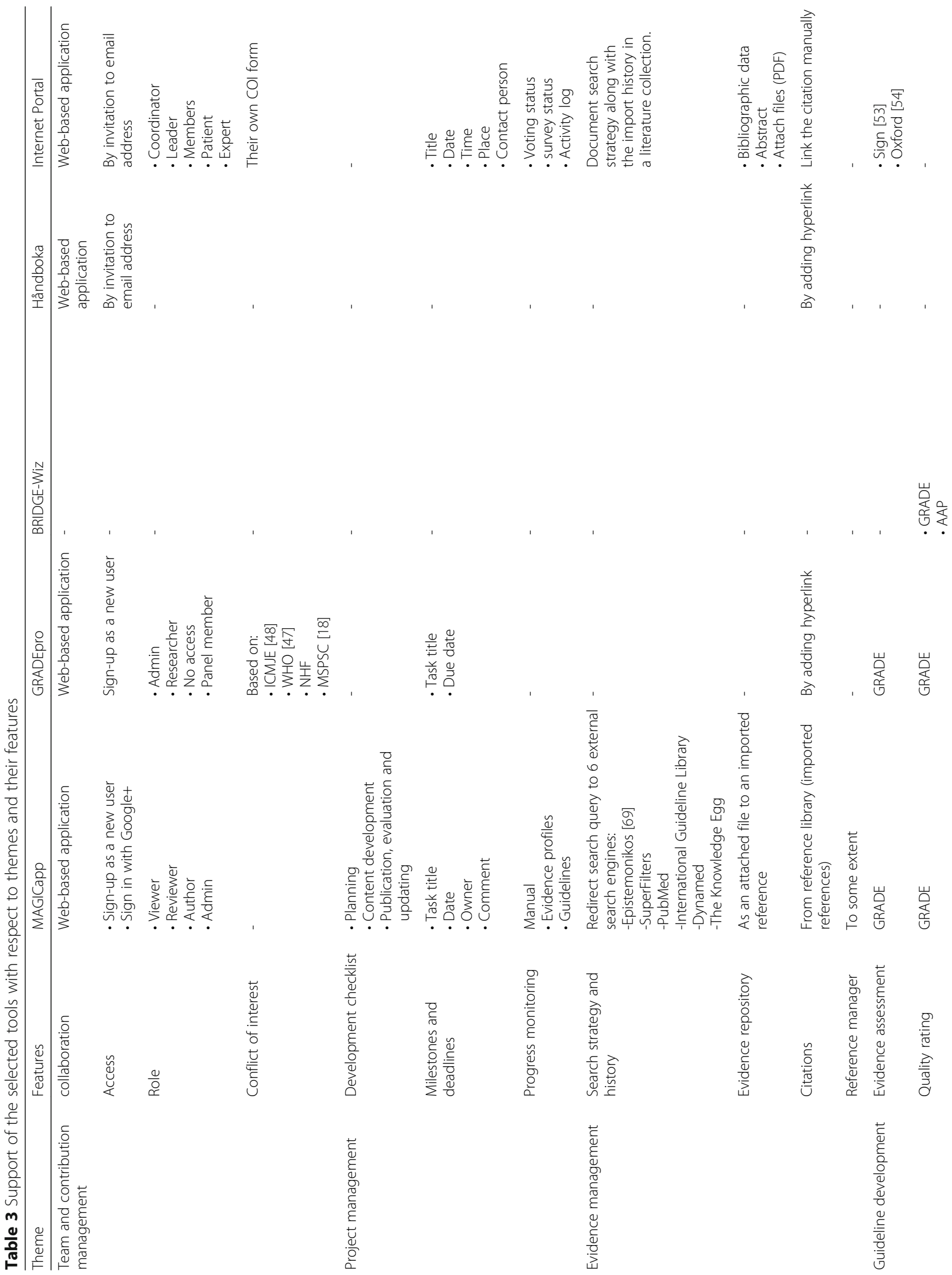




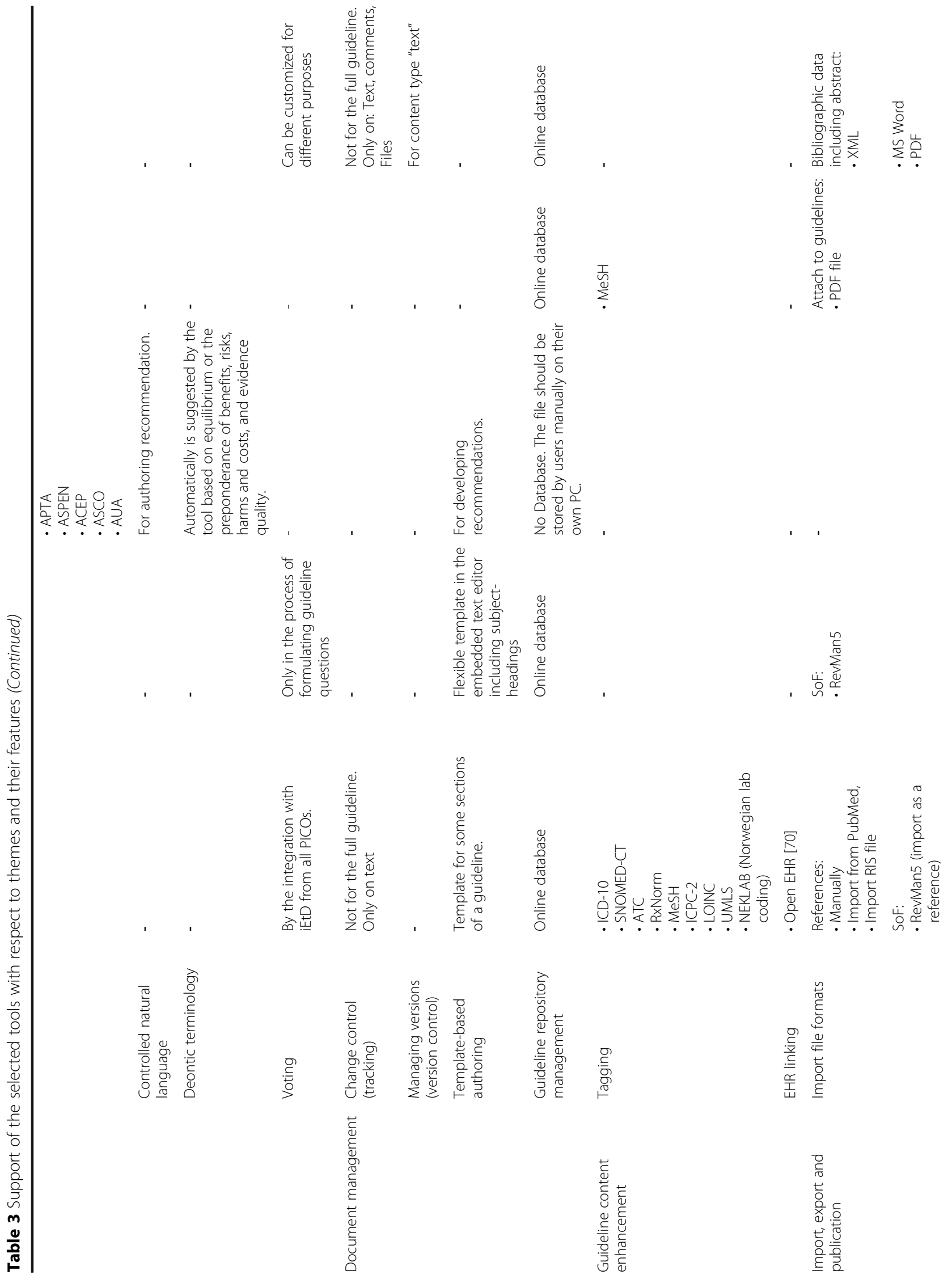




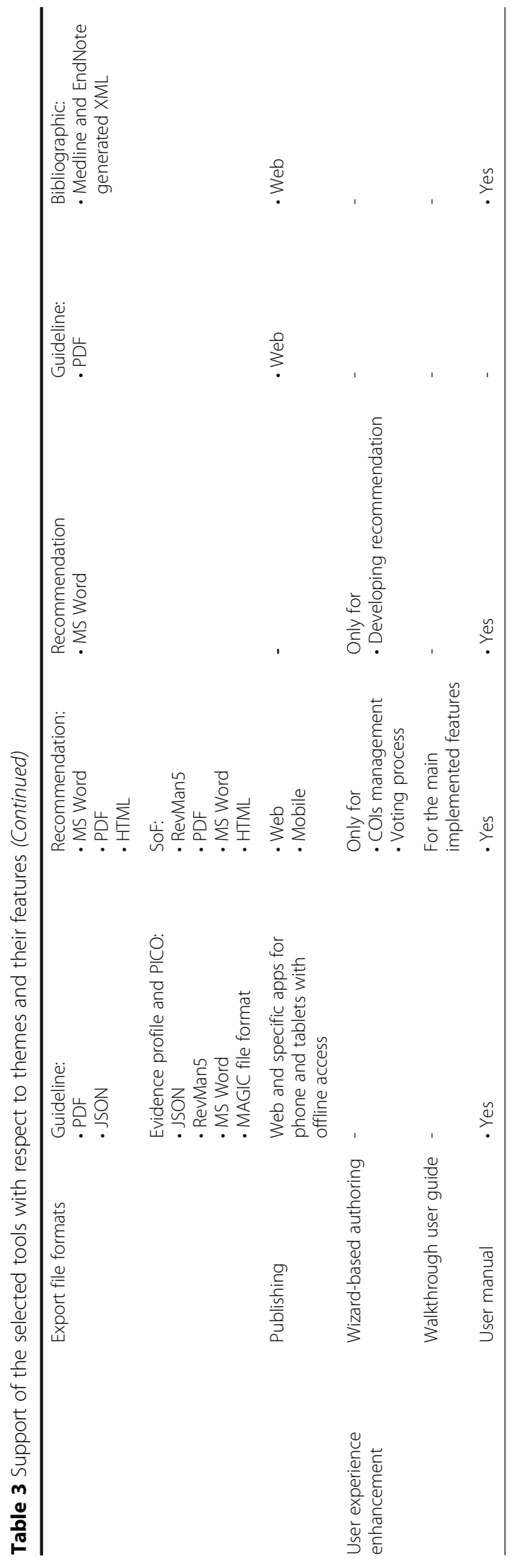


development environments [45] support the encoding of guidelines to facilitate content-based search, integration of electronic health records with guidelines and most importantly, executable decision and process support. [46]. As already stated, we regard this as a later step of GL deployment and implementation similar to software development, and not relevant for the initial GL authoring. Future work should explore the gaps authoring guideline content and for making them computerinterpretable. This will ease the flow of evidence to the clinic. The electronic development of clinical guidelines can facilitate the formalization step if they can communicate in terms of language, syntax, and semantic provided by the tools; therefore it reduces the challenges of the guideline maintenance process and therefore formalization process.

\section{Conclusion}

In this study we searched literature and contacted guideline development organisations to identify tools and CMS for development of GLs. We reviewed five academically reported GDTs (MAGICapp, GRADEpro, BRIDGE-Wiz, and Internet Portal) and Håndboka, as a representative of GL-specific CMSs. The results in this paper are useful for organisations and authors assessing and selecting a GDT.

By reading tool manuals, exploring the tools hands-on, comparing them against other, we uncovered, and proposed 8 themes that represent tool functionalities and features. Tools were selected according to their support of the guideline development process. Finally, the tools were characterized according to the 8 themes. Our purpose was not an overall GDT ranking, since GDTs are made for different purposes (i.e. only developing recommendations or a full guideline) and methodologies (i.e. developing recommendations based on GRADE). The identified themes can however be used for comparing tools, and in the future reconcile common features, and components. As guideline development manuals and methods are becoming more aligned, even standardized, this will drive alignment of GDTs. Furthermore, guideline representation and language standards encourage vendors to develop commercial applications for guideline implementations and EHR integration.

The tools may have limitations, and features, that are only possible to uncover after realistic use. Guideline author and editor requirements are also best captured when actually using the GDTs. Further study is required to understand if, and how, standard terminologies and ontologies impact the guideline encoding process. So, in summary:

What was already known?
Guideline authors mainly use text editors or CMS for authoring and publishing clinical guidelines.

The need for software support of GL authoring, maintenance and dissemination.

What this study added to our knowledge:

Identification of research prototypes and tools from literature, meetings, professional networks and health organizations.

Functionalities and features of representative GDTs.

Eight themes representing the GDT features.

Similarities and differences with regard to features among reviewed GDTs

The GDT application area and supported development methodology.

\section{Additional file}

Additional file 1: Details of the tools analysis. The additional file elaborated in details, when necessary, on the analysis of the reviewed tools (MAGICapp, GRADEpro, BRIDGE-Wiz, Håndboka, and Internet Portal) according to the presented results in Table 3. Each bold title represents the theme according to the uncovered themes in Table 2. (PDF $187 \mathrm{~kb}$ )

\section{Abbreviations \\ CMS: Content management systems; GDT: Guideline development tool; G-I- N: Guidelines International Network; GLs: Clinical guidelines; Internet Portal: Internet Portal for guideline development}

\section{Acknowledgements}

We are grateful for the support from project partners in the EviCare project: The Norwegian Knowledge Centre for the Health Services, DIPS ASA, Innlandet Hospital Trust and Oslo University Hospital.

\section{Funding}

We are grateful for the funding for the EviCare project (https://www.cristin.no/ app/projects/show.jsf?id=337417), from Norwegian Research Council grant no 193022.

\section{Availability of data and materials}

Not applicable.

\section{Authors' contributions}

SK and ØN developed the analysis design, SK performed the literature search and analysed the data under supervision of $\varnothing N$. SK performed the analysis and wrote the manuscript. $\varnothing \mathrm{N}$ supervised the analysis and co-wrote the manuscript. Both authors read and approved the final version of the manuscript.

Ethics approval and consent to participate Not applicable.

\section{Consent for publication \\ Not applicable.}

\section{Competing interests}

The authors declare that they have no competing interests.

\section{Publisher's Note}

Springer Nature remains neutral with regard to jurisdictional claims in published maps and institutional affiliations. 
Received: 6 April 2017 Accepted: 22 August 2017 Published online: 04 September 2017

\section{References}

1. Jaspers MW, Smeulers M, Vermeulen $H$, Peute LW. Effects of clinical decisionsupport systems on practitioner performance and patient outcomes: a synthesis of high-quality systematic review findings. J Am Med Inform Assoc. 2011;18(3):327-34.

2. Merritt TA, Palmer D, Bergman DA, Shiono PH. Clinical practice guidelines in pediatric and newborn medicine: implications for their use in practice. Pediatrics. 1997;99(1):100-14.

3. Steinberg E, Greenfield S, Mancher M, Wolman DM, Graham R. Clinical practice guidelines we can trust.1st edition. US National Academies Press; 2011.

4. WHO. WHO handbook for guideline development: World Health Organization (2nd edition); 2014. http://apps.who.int/iris/bitstream/10665/ 145714/1/9789241548960 eng.pdf.

5. Khodambashi $S$, Nytrø $\varnothing$, editors. Tool Support for Maintaining Clinical Guidelines: A Case Study. ECIME2015-9th European Conference on IS Management and Evaluation: ECIME 2015; 2015: Academic Conferences and publishing limited.

6. Kristiansen A, Brandt L, Alonso-Coello P, Agoritsas T, Akl EA, Conboy T, et al. Development of a novel multilayered presentation format for clinical practice guidelines. Chest. 2015;147:754-63

7. Shiffman RN, Michel G, Rosenfeld RM, Davidson C. Building better guidelines with BRIDGE-wiz: development and evaluation of a software assistant to promote clarity, transparency, and implementability. J Am Med Inform Assoc. 2012;19(1):94-101.

8. Brozek J, Oxman A, Schünemann H. GRADEpro, version 3.2 for windows. 2012.

9. Guyatt G, Vandvik PO. Creating clinical practice guidelines: problems and solutions. Chest. 2013;144(2):365-7.

10. Moher D, Liberati A, Tetzlaff J, Altman DG, Group P. Preferred reporting items for systematic reviews and meta-analyses: the PRISMA statement. PLoS Med. 2009;6(7):e1000097.

11. G-I-N. Guidelines International Network 2016 [cited 2016]. Available from: http://www.g-i-n.net.

12. Cruzes DS, Dyba T, editors. Recommended steps for thematic synthesis in software engineering. Empirical Software Engineering and Measurement (ESEM), 2011 International Symposium on; 2011: IEEE.

13. Vandvik PO, Brandt L, Alonso-Coello P, Treweek S, Akl EA, Kristiansen A, et al. Creating clinical practice guidelines we can trust, use, and share: a new era is imminent. Chest. 2013;144(2):381-9.

14. Treweek S, Oxman AD, Alderson P, Bossuyt PM, Brandt L, Brożek J, et al. Developing and evaluating communication strategies to support informed decisions and practice based on evidence (DECIDE): protocol and preliminary results. Implement Sci. 2013;8:6.

15. Kristiansen A, Vandvik P, Alonso-Coello P, Rigau D, Brandt L, Guyatt G. 313WS electronic multilayered guideline format: a novel structure and presentation of trustworthy guidelines at the point of care. BMJ Qual Saf. 2013;22(Suppl 1):A9-A10.

16. Brozek J, Akl E, Falck-Ytter Y, Kunstman P, Meerpohl J, Mustafa R, et al. P307 guideline development tool (GDT)-web-based solution for guideline developers and authors of systematic reviews. BMJ Qual Saf. 2013;22(Suppl 1):82.

17. Brozek J, Akl E, Falck-Ytter Y, Kunstman P, Meerpohl J, Mustafa R, et al. 046 guideline development tool (GDT)-web-based solution for guideline developers and authors of systematic reviews. BMJ Qual Saf. 2013;22(Suppl 1):A26-A.

18. Schünemann H, Mustafa R, Brozek J, Carrasco-Labra A, Brignardello-Petersen R, Wiecioch W. Saudi Arabian: Saudi Arabian Manual for Healthcare Guideline Development. http://www.moh.gov.sa/depts/Proofs/Documents/ SA\%20Handbook\%20_AB\%2030-6-14\%20v2.pdf.

19. Höhne W, Karge T, Siegmund B, Preiss J, Hoffmann J, Zeitz M, et al. An internet portal for the development of clinical practice guidelines. Appl Clin Inform. 2010;1(4):430.

20. Höhne W, Karge T, Siegmund B, Preiss J, Hoffmann J, Zeitz M, et al. An internet portal for the development of clinical practice guidelines. Appl Clin Inf. 2010;1:430-41. http://dx.doi.org/10.4338/ACl-2010-04-RA-0027. For personal or educational use only. aci-journal org. 2015:12-01

21. Peleg M. Computer-interpretable clinical guidelines: a methodological review. J Biomed Inform. 2013;46(4):744-63.

22. G-I-N. Guideline process - useful tools 2015 [cited 2016 May]. List of useful tools for the guideline process, their features and cross-compatibilities]. Available from: https://docs.google.com/spreadsheets/d/1XE-zbUFqK08nFyfhvB17tXeq_r2j5BRAeZZ4Xa5Axg/edit\#gid=0.
23. NursingCenter.com. CAN-IMPLEMENT৫: Clinical practice guidelines tailored for local use [cited 2016 May]. Available from: http://www.nursingcenter. com/evidencebasedpracticenetwork/canimplement.aspx?id=1917711.

24. Guyatt G, Oxman AD, Akl EA, Kunz R, Vist G, Brozek J, et al. GRADE guidelines: 1. Introduction-GRADE evidence profiles and summary of findings tables. J Clin Epidemiol. 2011;64(4):383-94.

25. Evidence D. Doctor Evidence platforms [cited 2016 May]. Available from: http://drevidence.com/.

26. Cochrane. Review Manager (RevMan) [cited 2016 May]. Cochrane's Informatics \& Knowledge Management Department (IKMD)]. Available from: http://tech.cochrane.org/revman.

27. Evidence-Partners. Distiller software [cited 2016 May]. Available from: https:// distillercer.com/.

28. Elmagarmid A FZ, Hammady H, llyas I, Khabsa M, Ouzzani M. Rayyan: a systematic reviews web app for exploring and filtering searches for eligible studies for Cochrane Reviews. 2014 21-26 Sep.

29. Institute JB. Joanna Briggs Institute system for the unified management, assessment and review of information (JBI SUMARI). 2014.

30. AHRQ. SRDR: Systematic Review Data Repository: Agency for Healthcare Research and Quality (AHRQ) [cited 2016 May]. Available from: http://srdr.ahrq.gov/.

31. EPPI-Centre. EPPI-Reviewer 4 2010. Available from: http://eppi.ioe.ac.uk/CMS/ Default.aspx?alias=eppi.ioe.ac.uk/cms/er4\&.

32. CREBP-SRA. CREBP Systematic Review Creator. Available from: http://crebpsra.com//. Accessed 9 May 2017.

33. Babineau J. Product review: covidence (systematic review software). J Can Health Libr Assoc. 2014;35(2):68-71.

34. Rada G, Pérez D, Capurro D, editors. Epistemonikos: a free, relational, collaborative, multilingual database of health evidence. Medinfo IMIA and IOS Press; 2013.

35. Rathbone J, Hoffmann T, Glasziou P. Faster title and abstract screening? Evaluating Abstrackr, a semi-automated online screening program for systematic reviewers. Syst Rev. 2015;4(1):1.

36. G-I-N. GIN guideline library- Guideline International Network [cited 2016 May]. Available from: http://www.g-i-n.net/library/international-guidelines-library.

37. Rathbone J, Carter M, Hoffmann T, Glasziou P. Better duplicate detection for systematic reviewers: evaluation of systematic review assistantDeduplication module. Syst Rev. 2015;4(1):1-6. 10.1186/2046-4053-4-6.

38. Evidence-Prime. GDTs database of evidence profiles [cited 2016 May]. Available from: http://dbep.gradepro.org/search.

39. Brozek J, Oxman A, Schünemann H. GRADEpro.[computer program]. Version 32 for windows. 2008.

40. Khodambashi $\mathrm{S}$, Gilstad H, Nytrø $\varnothing$. Usability evaluation of clinical guidelines on the web using eye-tracker. Stud Health Technol Inform. 2016;228:95.

41. Khodambashi $S$, Nytrø $\varnothing$, editors. Usability Evaluation of Published Clinical guidelines on the Web: A Case Study. 2016 IEEE 29th International Symposium on Computer-Based Medical Systems (CBMS); 2016: IEEE Conference Publicationsm. doi:10.1109/CBMS.2016.11.

42. Khodambashi $S$, Wang Z, Nytrø $\varnothing$. Reality versus user's perception in finding answer to clinical questions in published National Guidelines on the web: an empirical study. Procedia Comput Sci. 2015;63:268-75.

43. Khodambashi S, Perry A, Nytrø $\varnothing$. Comparing user experiences on the search-based and content-based recommendation ranking on stroke clinical guidelines-a case study. Procedia Comput Sci. 2015;63:260-7.

44. Khodambashi $S$, Gilstad $H$, Nytrø $\varnothing$. Usability evaluation of clinical guidelines on the web using eye-tracker. Medical informatics Europe (MIE 2016); 2016: Accepted, under publishing process.

45. Peleg M, Tu S, Bury J, Ciccarese P, Fox J, Greenes RA, et al. Comparing computer-interpretable guideline models: a case-study approach. J Am Med Inform Assoc. 2003;10(1):52-68.

46. De Clercq PA, Blom JA, Korsten HH, Hasman A. Approaches for creating computer-interpretable guidelines that facilitate decision support. Artif Intell Med. 2004;31(1):1-27.

47. World-Health-Organization. WHO Handbook for Guideline Development Process - World Health Organization 2010 [cited 2015 10.03.2015]. Available from: http://www.who.int/hiv/topics/mtct/grc_handbook_ mar2010_1.pdf.

48. Editors ICoMJ. Conflict of Interest Disclosure Forms 2015 [cited 201522 July 2015]. Available from: http://www.icmje.org/about-icmje/faqs/conflict-ofinterest-disclosure-forms/.

49. Qaseem A, Forland F, Macbeth F, OllenschlÃ̃lger G, Phillips S, van der Wees P. Guidelines international network: toward international standards for clinical practice guidelines. Ann Intern Med. 2012;156(7):525-31. 
50. Terrace L. Development and validation of an international appraisal instrument for assessing the quality of clinical practice guidelines: the AGREE project. Qual Saf Health Care. 2003;12:18-23.

51. Guideline Development Checklist 2014 [cited 201522 July 2015]. Available from: http://cebgrade.mcmaster.ca/guidelinechecklistonline.html.

52. WHO. WHO Handbook for Guideline Development: World Health Organization; 20122012

53. SIGN. Scottish Intercollegiate Guidelines Network Methodology checklist. SIGN. 2014. Available from: http://www.sign.ac.uk/checklists-and-notes.html.

54. Oxford. Oxford Centre for Evidence-Based Medicine. Levels of evidence [cited 2016 May]. Available from: http://www.sign.ac.uk/checklists-and-notes.html.

55. Goldet G, Howick J. Understanding GRADE: an introduction. J Evid Based Med. 2013:6(1):50-4

56. West SL, King V, Carey TS, Lohr KN, McKoy N, Sutton SF, et al. Systems to rate the strength of scientific evidence: Agency for Healthcare Research and Quality, US Department of Health and Human Services; AHRQ Publication No. 02-E016 April 2002.

57. Guyatt GH, Oxman AD, Vist GE, Kunz R, Falck-Ytter Y, Alonso-Coello P, et al. GRADE: an emerging consensus on rating quality of evidence and strength of recommendations. BMJ. 2008;336(7650):924-6.

58. Guyatt G, Gutterman D, Baumann MH, Addrizzo-Harris D, Hylek EM, Phillips $B$, et al. Grading strength of recommendations and quality of evidence in clinical guidelines: report from an American College of Chest Physicians task force. Chest. 2006;129(1):174-81.

59. Yale University. Available Versions of BridgeWiz 2011 [cited 2016 May]. Available from: http://gem.med.yale.edu/BRIDGE-Wiz/.

60. Shiffman RN, Michel G, Krauthammer M, Fuchs NE, Kaljurand K, Kuhn T. Writing clinical practice guidelines in controlled natural language. Controlled Natural Language: Springer; 2010. p. 265-280.

61. Organization WH. International statistical classification of diseases and health related problems (The) ICD-10: World Health Organization; 2004.

62. Donnelly K. SNOMED-CT. the advanced terminology and coding system for eHealth. Stud Health Technol Inform. 2006;121:279. https://books.google.no/ books?hl=en\&lr=lang_en\&id=Tw5eAtsatiUC\&oi=fnd\&pg=PA1\&dq=International +statistical+classification+of+diseases+and+health+related+problems+(The)+ICD10\&ots=037_mqFhJ\&sig=SNAl2HuzMXLSWNFdzvcOagoKyts\&redir_esc=y\#v= onepage\&q=International\%20statistical\%20classification\%20of\%20diseases\% 20and10\&f=false.

63. Miller $\mathrm{G}$, Britt $\mathrm{H}$. A new drug classification for computer systems: the ATC extension code. Int J Biomed Comput. 1995;40(2):121-4.

64. Liu S, Ma W, Moore R, Ganesan V, Nelson S. RxNorm: prescription for electronic drug information exchange. IT Prof. 2005;7(5):17-23.

65. Nelson SJ, Johnston WD, Humphreys BL. Relationships in medical subject headings (MeSH). Relationships in the Organization of Knowledge: Springer; 2001. p. 171-184

66. Lamberts H, Okkes I. ICPC-2, international classification of primary care. 1998 https://link.springer.com/chapter/10.1007/978-94-015-9696-1_11.

67. McDonald CJ, Huff SM, Suico JG, Hill G, Leavelle D, Aller R, et al. LOINC, a universal standard for identifying laboratory observations: a 5-year update. Clin Chem. 2003:49(4):624-33.

68. Lindberg DA, Humphreys BL, McCray AT. The unified medical language system. Methods Inf Med. 1993;32(4):281-91.

69. About Epistemonikos [cited 201527 July 2015]. Available from: http://www. epistemonikos.org/en/about_us/who_we_are

70. Beale T, Heard S, Kalra D, Lloyd D. OpenEHR architecture overview. The OpenEHR Foundation. 2006.

\section{Submit your next manuscript to BioMed Central and we will help you at every step:}

- We accept pre-submission inquiries

- Our selector tool helps you to find the most relevant journal

- We provide round the clock customer support

- Convenient online submission

- Thorough peer review

- Inclusion in PubMed and all major indexing services

- Maximum visibility for your research

Submit your manuscript at www.biomedcentral.com/submit
Biomed Central 